\title{
Strive for kidney health for everyone during COVID-19; the possible theme for the world kidney day 2021
}

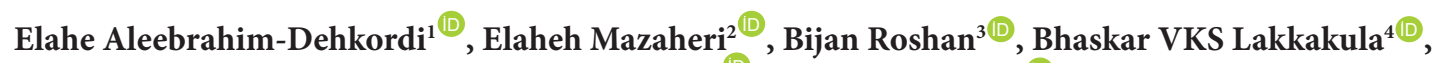 \\ Ali Hasanpour-Dehkordi ${ }^{*}$, Maryam Khosravian ${ }^{6}{ }^{\circledR}$, Aiyoub Pezeshgi ${ }^{* * \mathbb{C}}$ \\ ${ }^{1}$ Medical Plants Research Center, Basic Health Sciences Institute, Shahrekord University of Medical Sciences, Shahrekord, Iran \\ ${ }^{2}$ Health Information Technology Research Center, Student Research Committee, Department of Medical Library and Information Sciences, \\ School of Management and Medical Information Sciences, Isfahan University of Medical Sciences, Isfahan, Iran \\ ${ }^{3}$ Division of Nephrology, Scripps Clinic, La Jolla, California, USA \\ ${ }^{4}$ Department of Zoology, Guru Ghasidas Vishwavidyalaya, Bilaspur, India \\ ${ }_{5}^{5}$ Social Determinants of Health Research Center, School of Allied Medical Sciences, Shahrekord University of Medical Sciences, Shahrekord, \\ Iran \\ ${ }^{6}$ Institute of Biology, Martin Luther University Halle-Wittenberg, Halle (Saale), Germany \\ ${ }^{7}$ Department of Nephrology and Zanjan Metabolic Disease Research Center, School of Medicine, Zanjan University of Medical Sciences, \\ Zanjan, Iran
}

\section{A R T I C L E I N F O}

\section{Article Type:}

Mini Review

\section{Article History:}

Received: 10 August 2020

Accepted: 1 September 2020

Published online: 7 September 2020

\begin{abstract}
A B S T RA C T
Increasing awareness regarding CKD and self-care during COVID-19 pandemic has become the most important aspect for the nephrologists. Hence it is appropriate that the theme of the forthcoming World Kidney Day on 11 March 2021 should be "Strive for kidney health for everyone during COVID-19"
\end{abstract}

Keywords: Chronic kidney disease, COVID-19, World Kidney Day, Severe acute respiratory syndrome coronavirus 2 (SARS-CoV-2), Collapsing glomerulopathy, End-stage renal disease, Hemodialysis, Renal failure

Implication for health policy/practice/research/medical education:

Proteinuria, hematuria, and acute kidney injury are some of the clinical manifestations of renal failure in COVID-19 patients. Additionally, collapsing glomerulopathy with de novo nephrotic syndrome with acute renal impairment in COVID-19 patients has been described and recently been linked with APOL1 (apolipoprotein L1) in African American patients.

Please cite this paper as: Aleebrahim-Dehkordi E, Mazaheri E, Roshan B, Lakkakula BVKS, Hasanpour-Dehkordi A, Khosravian M, et al. Strive for kidney health for everyone during COVID-19; the possible theme for the world kidney day 2021. J Nephropharmacol. 2021;10(2):e12. DOI: 10.34172/npj.2021.12.

\section{Introduction}

Since 2006, World Kidney Day (WKD) is observed on the second Thursday of March each year in more than 150 countries around the world. WKD provides an opportunity to raise concerns about kidney disease and its impact on public health worldwide. Kidney failure is one of the major global public health problems and the number of individuals with chronic kidney disease (CKD) is increasing every year $(1,2)$. The growing global prevalence of CKD and high economic burden it imposes on the healthcare systems is making it a global health concern by all healthcare administrators (3). CKD and progressive kidney failure are associated with major adverse health consequences, including cardiovascular disease and death $(4,5)$. Despite many efforts to prevent ESRD (end-stage renal disease), the number of these patients is increasing worldwide (6). ESRD treatment options such as hemodialysis and kidney transplantation, adversely affect the life expectancy and social life of the patient leading to impaired quality of life $(7,8)$. Patients undergoing hemodialysis have higher levels of inflammation and oxidative stress, which are the main risk factors for cardiovascular mortality in these patients $(9,10)$. Although a lot of people around the world suffer from $\mathrm{CKD}$, many do not have necessary information about their disease. Hence it is necessary to take effective measures to promote the knowledge about CKD and its burden on overall health status of an individual.

\section{Methods}

International databases including Google Scholar, Web of Science, Scopus, EBSCO and PubMed were considered 
for search of relevant articles for this mini-review. The keywords were; chronic kidney disease, COVID-19, World Kidney Day, severe acute respiratory syndrome coronavirus 2 (SARS-CoV-2), collapsing glomerulopathy, end-stage renal disease, hemodialysis and renal failure.

\section{Coronavirus disease 2019 (COVID-19)}

Coronavirus disease 2019 (COVID-19), the respiratory illness caused by severe acute respiratory syndrome coronavirus 2 (SARS-CoV-2). SARS-CoV-2 belongs to a large family of single-stranded RNA viruses. Clinical signs of novel coronavirus patients were first described in December 2019 (11). The virus mainly affects the respiratory system of the patients and continues to spread (12). The current condition of COVID-19 pandemic around the world is extremely severe and affects important economic, social and medical aspects of life. Many vaccines are underway, some are in phase three trials, but it would be a while before a safe and effective vaccine becomes available for the public. In the meantime, public health measures to control the infection are necessary to limit the damage related to COVID-19. Based on first-hand experience of management and controlling SARS-Cov and MERS (Middle East respiratory syndrome) infections, the World Health Organization has recommended infection control interventions to reduce the overall risk of transmitting COVID-19. These interventions include avoiding close and direct contact with people with severe respiratory infections, washing hands frequently, especially after direct contact with patients, and avoiding unprotected contact with wild and domestic animals (13, 14). Currently, the number of individuals with COVID-19 and related mortality is increasing rapidly worldwide (15).

\section{COVID-19 and kidney}

The clinical characteristics of renal failure as well as post-mortem renal histopathological changes in patients with COVID-19 are well documented $(16,17)$. Proteinuria, hematuria, and acute kidney injury are some of the clinical manifestations of renal failure in COVID-19 patients. Collapsing glomerulopathy with de novo nephrotic syndrome and acute kidney injury in COVID-19 patients has been described and recently been linked with apolipoprotein L1 (APOL1) in African American patients (18). The presence of viral particles in the proximal renal tubules, which were identical to SARS-CoV-2 and other features of virus assembly, provide evidence for direct renal infestation by SARS-CoV-2 (19). On the other hand, several symptoms of varying severity have been observed in COVID-19 patients with a history of kidney disease (20-22). Hence, early diagnosis and early supportive measures and interventions can reduce mortality in patients with COVID-19 (23).

Since the beginning of the COVID-19 outbreak, there has been a serious interruption in prevention and treatment services for other non-communicable diseases.
On the other hand, the anxiety and fear created by the COVID-19 outbreak caused patients with CKD to ignore or delay treatment and pay no attention to its potential risks (24). Diabetes, hypertension and cardiovascular disease are the major causes of CKD in adults, and all of them are associated with high mortality and morbidity in COVID-19 disease. The pathogenicity of the SARS$\mathrm{CoV}-2$, its rapid and efficient spread rate and the higher mortality rate in patients with CKD comorbidities makes this population extremely vulnerable to severe impact of this disease. Early detection of CKD and prevention of disease progression is the first vital step in the management of kidney related problems. As CKD has become a global health hazard and the risk of severe COVID-19 is three times greater in patients with CKD than in patients without CKD, a comprehensive program for the prevention, control, care, treatment and awareness of the patients with kidney diseases is necessary. In the absence of any comprehensive effective treatment protocol for the novel SARS-CoV-2, the health literacy of the individuals with CKD should be increased to encourage the patients with kidney disease to strictly adhere to the prevention protocols and to observe a healthy lifestyle.

The devastating physical and psychological effects of this virus, as well as the consequences of quarantine measures, have a profound effect on patients with kidney disease. All activities and training aimed at increasing patients' awareness should focus on preventive behaviors, recognition of risk factors and knowledge of how to live in coronavirus pandemic for patients with kidney disease. Special self-care is effective in delaying advancement of kidney disease, reducing mortality and costs, and increasing the quality of life of these patients (25). Lack of equal access to adequate health facilities and high costs of care and treatment have led to concentration on the concept of self-care (26). Self-care activities reduce disease symptoms, complications, as well as the number of readmissions and lead to faster recovery in patients with a wide range of conditions (27). Lack of knowledge of selfcare is one of the reasons for the patient's readmission and frequent referrals to health care centers (28). The self-care and active participation in self-care programs for chronic diseases, including CKD, and COVID-19 empower patients and lead to increased happiness and morale, as well as reduced psychological stress. In hemodialysis patients, self-care programs increase the use of appropriate coping mechanisms and build self-confidence to avoid feelings of hopelessness, and depression (29).

The fastest and most effective way to achieve social justice is to provide people with universal access to education in all aspects. Training is an important part of any educational program which is seen as one of the main responsibilities of health professionals, including physicians, nurses, and other providers. In dialysis patients, training is associated with improving nutritional status, which in turn is associated with reduced side effects of the 
disease and even mortality (26). As patients with diabetes and hypertension are at higher risk for kidney disease, they may need to have regular kidney function testing to detect early-stage kidney failure. In addition, patients with CKD are at higher risk for SARS-CoV-2 infection and requiring regular follow-ups and testing even after following quarantine and social distancing limitations. Long term sedentary lifestyle is associated with many physical and mental disorders including kidney disease, and it is important to follow good nutritional principles and maintain adequate physical activity during home quarantine (30).

Training for self-care should be employed and adequate kidney health screening and monitoring of renal health by healthcare professionals should be continued with greater power than ever under the COVID-19 pandemic. Regular care for chronic diseases, including CKD, should not be interrupted by the pandemic.

\section{Conclusion}

Increasing awareness regarding $\mathrm{CKD}$ and self-care during COVID-19 pandemic has become the most important aspect for the nephrologists. Hence it is appropriate that the theme of the forthcoming World Kidney Day on 11 March 2021 should be "Strive for kidney health for everyone during COVID-19".

\section{Authors' contribution}

EAD, EM and AHD prepared the primary draft. AP edited the paper. MK, LBVKS, MK and BR conducted further edits. All authors read and approved the final paper.

\section{Conflicts of interest}

The authors declared no competing interests.

\section{Ethical considerations}

Ethical issues (including plagiarism, data fabrication, double publication) have been completely observed by the authors.

\section{Funding/Support}

None.

\section{References}

1. Szczech LA, Harmon W, Hostetter TH, Klotman PE, Powe NR, Sedor JR, et al. World Kidney Day 2009: problems and challenges in the emerging epidemic of kidney disease. J Am Soc Nephrol. 2009;20:453-5. doi:10.1681/ASN.2009010041.

2. Finkelstein FO, Wuerth D, Finkelstein SH. Health related quality of life and the CKD patient: challenges for the nephrology community. Kidney Int. 2009;76:946-52. doi:10.1038/ki.2009.307.

3. Luyckx VA, Tonelli M, Stanifer JW. The global burden of kidney disease and the sustainable development goals. Bull World Health Organ. 2018; 96(6):414-422D. doi:10.2471/ BLT.17.206441.

4. Go AS, Chertow GM, Fan D, McCulloch CE, Hsu
CY. Chronic kidney disease and the risks of death, cardiovascular events, and hospitalization. N Engl J Med. 2004; 351:1296-305. doi: 10.1056/NEJMoa041031.

5. Anavekar NS, McMurray JJ, Velazquez EJ, Solomon SD, Kober L, Rouleau JL, et al. Relation between renal dysfunction and cardiovascular outcomes after myocardial infarction. N Engl J Med. 2004;351:1285-95. doi: 10.1056/ NEJMoa041365.

6. Iseki K. Factors influencing the development of end-stage renal disease. Clin Exp Nephrol. 2005;9:5-14. doi: 10.1007/ s10157-005-0341-3.

7. Oliveira AP, Schmidt DB, Amatneeks TM, Santos JC, Cavallet LH, Michel RB. Quality of life in hemodialysis patients and the relationship with mortality, hospitalizations and poor treatment adherence. J Bras Nefrol. 2016;38:411420. doi: 10.5935/0101-2800.20160066.

8. Unruh ML, Hess R. Assessment of health-related quality of life among patients with chronic kidney disease. Adv Chronic Kidney Dis. 2007;14:345-52. doi:10.1053/j. ackd.2007.07.011.

9. Astor BC, Hallan SI, Miller ER, 3rd, Yeung E, Coresh J. Glomerular filtration rate, albuminuria, and risk of cardiovascular and all-cause mortality in the US population. Am J Epidemiol. 2008;167:1226-34. doi:10.1093/aje/ kwn033.

10. Wang Z, Yu C, Li XH, Deng BQ. The prognostic value of oxidative stress and inflammation in Chinese hemodialysis patients. Ren Fail. 2017;39:54-8. doi:10.1080/088602 2x.2016.1244078.

11. Yang Y, Lu Q, Liu M, Wang Y, Zhang A, Jalali N, et al. Epidemiological and clinical features of the 2019 novel coronavirus outbreak in China. MedRxiv. 2020:2020.02.10.20021675. doi:10.1101/2020.02.10.200216 75.

12. Lai CC, Shih TP, Ko WC, Tang HJ, Hsueh PR. Severe acute respiratory syndrome coronavirus 2 (SARS-CoV-2) and coronavirus disease-2019 (COVID-19): The epidemic and the challenges. Int J Antimicrob Agents. 2020;55:105924. doi:10.1016/j.ijantimicag.2020.105924.

13. Guan W-j, Ni Z-y, Hu Y, Liang W-h, Ou C-q, He J-x, et al. Clinical Characteristics of Coronavirus Disease 2019 in China. N Engl J Med. 2020;382:1708-20. doi: 10.1056/ NEJMoa2002032.

14. Harper CA, Satchell LP, Fido D, Latzman RD. Functional Fear Predicts Public Health Compliance in the COVID-19 Pandemic. Int J Ment Health Addict. 2020. doi: 10.1007/ s11469-020-00281-5.

15. Bedford J, Enria D, Giesecke J, Heymann DL, Ihekweazu C, Kobinger G, et al. COVID-19: towards controlling of a pandemic. Lancet. 2020; 395:1015-8. doi: 10.1016/s01406736(20)30673-5.

16. Chen L, Liu HG, Liu W, Liu J, Liu K, Shang J, et al. [Analysis of clinical features of 29 patients with 2019 novel coronavirus pneumonia]. Zhonghua Jie He He Hu Xi Za Zhi. 2020; 43:E005. doi:10.3760/cma.j.issn.1001-0939.2020.0005.

17. Su H, Yang M, Wan C, Yi L-X, Tang F, Zhu H-Y, et al. Renal histopathological analysis of 26 postmortem findings of patients with COVID-19 in China. Kidney Int. 2020; 98:219-27. doi:10.1016/j.kint.2020.04.003.

18. Wu H, Larsen CP, Hernandez-Arroyo CF, Mohamed 
MMB, Caza T, Sharshir M, et al. AKI and Collapsing Glomerulopathy Associated with COVID-19 and APOL1 High-Risk Genotype. J Am Soc Nephrol. 2020;31:16881695. doi: 10.1681/ASN.2020050558.

19. Farkash EA, Wilson AM, Jentzen JM. Ultrastructural evidence for direct renal infection with SARS-CoV-2. J Am Soc Nephrol. 2020;31:1683-7. doi:10.1681/asn.2020040432.

20. Huang C, Wang Y, Li X, Ren L, Zhao J, Hu Y, et al. Clinical features of patients infected with 2019 novel coronavirus in Wuhan, China. Lancet. 2020;395:497-506. doi: 10.1016/ s0140-6736(20)30183-5.

21. Asgharpour M, Zare E, Mubarak M, Alirezaei A. COVID-19 and Kidney Disease: Update on Epidemiology, Clin-ical Manifestations, Pathophysiology and Management. J Coll Physicians Surg Pak 2020;30:S19-25.

22. Naicker S, Yang C-W, Hwang S-J, Liu B-C, Chen J-H, Jha V. The Novel Coronavirus 2019 epidemic and kidneys. KidneyInt. 2020;97:824-8. doi: 10.1016/j.kint.2020.03.001.

23. Li $\mathrm{Z}$, Wu M, Yao J, Guo J, Liao X, Song $\mathrm{S}$, et al. Caution on Kidney Dysfunctions of COVID-19 Patients. MedRxiv. 2020:2020.02.08.20021212. doi: $10.1101 / 2020.02 .08 .20021212$.

24. Mertens G, Gerritsen L, Duijndam S, Salemink E, Engelhard IM. Fear of the coronavirus (COVID-19): Predictors in an online study conducted in March 2020. J Anxiety Disord. 2020;74:102258. doi: 10.1016/j.janxdis.2020.102258.

25. Avramovic M, Stefanovic V. Health-related quality of life in different stages of renal failure. Artif Organs. 2012; 36(7):581-9. doi: 10.1111/j.1525-1594.2011.01429.x.

26. Fukuhara S, Lopes AA, Bragg-Gresham JL, Kurokawa K, Mapes DL, Akizawa T, et al. Health-related quality of life among dialysis patients on three continents: the Dialysis Outcomes and Practice Patterns Study. Kidney Int. 2003; 64:1903-10. doi: 10.1046/j.1523-1755.2003.00289.x.

27. Peuhkuri K, Sihvola N, Korpela R. Diet promotes sleep duration and quality. Nutr Res. 2012;32:309-19. doi:10.1016/j.nutres.2012.03.009.

28. Chan RSM, Woo J. Prevention of overweight and obesity: how effective is the current public health approach. Int J Environ Res Public Health. 2010;7:765-83. doi: 10.3390/ ijerph7030765.

29. Tsay SL, Healstead M. Self-care self-efficacy, depression, and quality of life among patients receiving hemodialysis in Taiwan. Int J Nurs Stud. 2002;39:245-51. doi: 10.1016/ s0020-7489(01)00030-x.

30. Muscogiuri G, Barrea L, Savastano S, Colao A. Nutritional recommendations for CoVID-19 quarantine. Eur J Clin Nutr. 2020;74:850-1. doi: 10.1038/s41430-020-0635-2.

Copyright $\odot 2021$ The Author(s); Published by Published by Society of Diabetic Nephropathy Prevention. This is an open-access article distributed under the terms of the Creative Commons Attribution License (http://creativecommons.org/licenses/by/4.0), which permits unrestricted use, distribution, and reproduction in any medium, provided the original work is properly cited. 